\title{
Itinerario de Competencia Dixital: o nivel avanzado
}

\author{
Itinerary of Digital Competence: the advanced level \\ Eduardo Rodríguez-Machado*, Emilio J. Veiga** Mercedes González-Sanmamed*** \\ *Universidad Internacional de la Rioja, **Universidad de Santiago de Compostela, ***Universidade da Coruña
}

\begin{abstract}
Resumen
Este artigo está enmarcado dentro do itinerario de competencia dixital (nivel avanzado) proposto pola Comisión TIC da rede permanente de formación do profesorado da Consellería de Educación de Galicia. Este curso desenvólvese totalmente en rede sen que exista previsión de ningunha sesión presencial. Sabemos que a tarefa de titoría resulta polo tanto moi importante no bo funcionamento do mesmo. Pretendemos explicar cómo funciona os itinerarios de competencias dixitais dende o perfil do titor do curso.

O asesoramento no funcionamento da Plataforma, as axudas na resolución de dificultades, as correccións e as avaliacións serán tarefas primordiais no traballo do titor.
\end{abstract}

Palabras claves: competencias dixitais, nivel avanzado, módulos, itinerario.

\begin{abstract}
This article is framed in the itinerary of digital competence (advanced level) suggested by the TIC Commission of the permanent net of formation of the teaching staff of the Department of Education of Galicia. This course copes totally in net without there being forecast of any eyewitness session. We know that the task of tuition is therefore very important in the good functioning of it. We intend to explain how it works the itineraries of digital competences from the profile of the tutor of the course. The advice in the functioning of the Platform, the helps in the resolution of difficulties, the corrections and the evaluations will be fundamental tasks in the work of the tutor.
\end{abstract}

Keywords: digital competences, advanced level, modules, itinerary.

\section{Competencia dixital do profesorado}

No proceso de integración das TIC no sistema educativo galego detéctase a necesidade de proporcionar ao profesorado instrumentos de valoración para coñecer a propia competencia TIC docente e poder elixir dentro da oferta formativa aquelas actividades que mellor respondan ás súas necesidades. Esta motivación leva á Consellería de Educación e Ordenación Universitaria a establecer un marco de referencia baseado en catro dimensións:

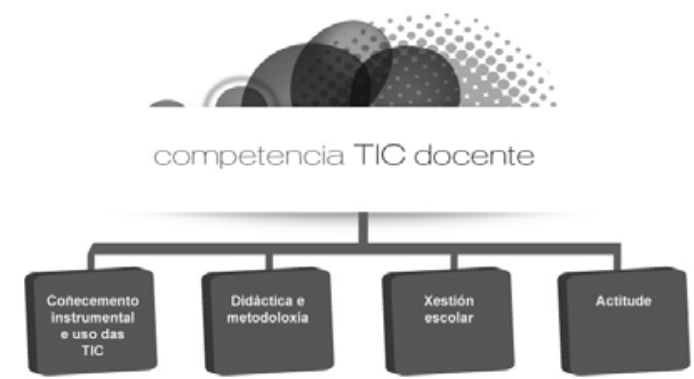

Figura 1: Dimensións

En relación con estas dimensións establécense cinco niveis de competencia TIC, que se medirán sobre a base duns indicadores para cada unha das dimensións:

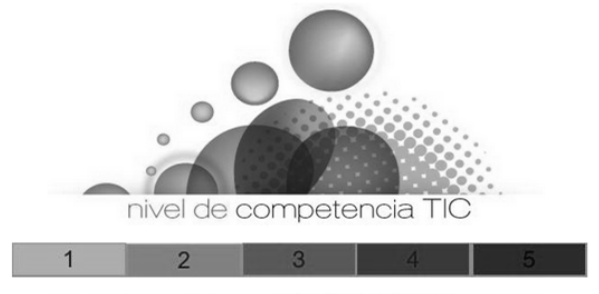

Figura 2: Niveis de competencia.

Para poder medir o nivel de competencia TIC dispoñemos nunha aula virtual en Platega con cinco cuestionarios de autoavaliación (para facelos é necesario introducir o contrasinal "abalar" cando solicite a inscrición).

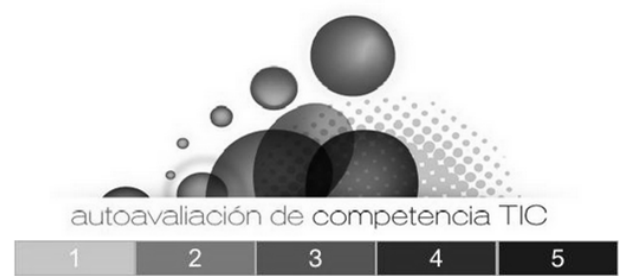

Figura 3: Cuestionario de autoavalición.

En correspondencia con estes niveis, deseñouse un itinerario formativo de competencia TIC docente con cinco cursos: 


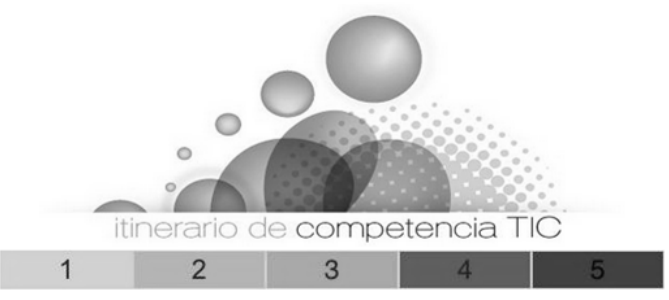

Figura 4: Itinerario Formativo

Poderán realizarse mediante a correspondente inscrición en Fprofe. Os resultados de cada cuestionario miden o nivel de competencia e sinalan a conveniencia de realizar un determinado curso dentro do itinerario formativo TIC. Esta ferramenta de autoavaliación pretende facilitar ao profesorado un coñecemento o máis aproximado posible da formación que necesita para unha mellor integración das TIC na docencia.

\section{Obxectivos}

O obxectivo principal de todo este proceso de formación é o de mellorar as competencias dixitais do profesorado e facilitar a mellora da calidade do ensino fomentando a aplicación práctica desta formación adquirida.

Os obxectivos que se pretenden son:

1. Ampliar a competencia dixital do profesorado.

2. Fomentar a experimentación metodolóxica.

3. Adquirir destrezas no uso de software específico

4. Ter un amplo coñecemento das posibilidades das ferramentas Ardora, eXe Learning e Lim.

5. Ser quen de desenvolver proxectos didácticos interactivos en contorno web para as aulas.

6. Coñecer distintos xeitos do emprego didáctico do material elaborado.

7. Desenvolver recursos SCORM susceptibles de ser introducidos en plataformas de teleformación.

8. Analizar e propor actuacións ante incidencias relacionadas coa aplicación das TIC no ensino.

9. Progresar no uso dos espazos virtuais (servizos web, moodle, etc).

10. Deseñar estratexias para a utilización das Tecnoloxías da Información e a Comunicación en propostas de traballo cooperativo.

Cada módulo inclúe os contidos conceptuais e as tarefas correspondentes, que deberán ser completadas polas persoas participantes na data indicada, e que aparece expresamente reflectida na descrición da tarefa.

\section{Seguimento dun dos niveis de competencias}

No noso caso temos tutorizado un dos niveis de formación en competencias dixitais, en concreto no nivel avanzado que se desenvolvemento no $2^{\circ}$ trimestre do curso 2014-2015.

Este curso está enmarcado dentro do itinerario de competencia dixital proposto pola Comisión TIC da rede permanente de formación do profesorado. Dentro deste itinerario de formación TIC existen cinco niveis:

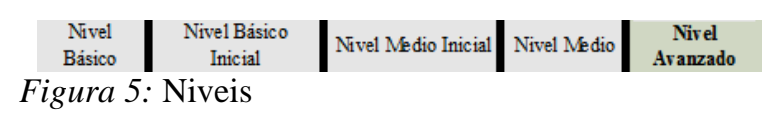

Empregamos a nova plataforma de teleformación "PLATEGA", que funciona a través da aplicación web MOODLE (versión 2.6.).

Estes cursos desenvólvense totalmente en rede sen que exista previsión de ningunha sesión presencial. Sabemos que a tarefa de titoría resulta polo tanto moi importante no bo funcionamento do mesmo. O asesoramento no funcionamento da plataforma, as axudas na resolución de dificultades, as correccións e as avaliacións serán tarefas primordiais no traballo do titor. Pero ademais da relación directa co titor, dispoñemos de foros como lugar para a discusión, para a consulta ou para a reflexión. Os foros facilitan a comunicación entre o alumnado e o titor e tamén entre todos os participantes no curso, podendo funcionar como centros de aprendizaxe común onde expoñer as nosas dúbidas ou preguntas, as dos outros participantes, as respostas, as suxestións...

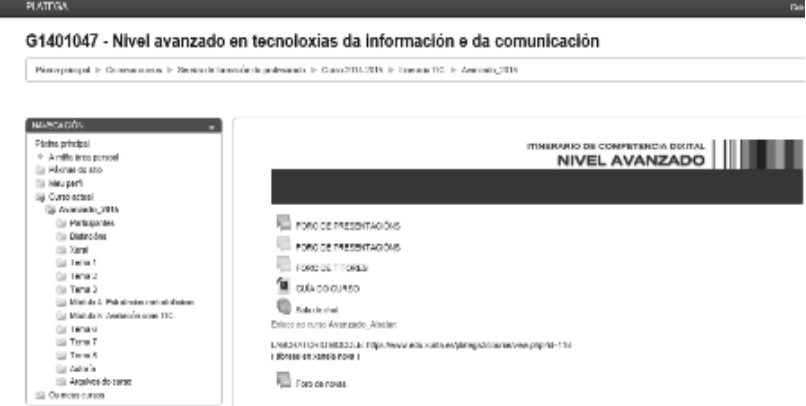

Figura 6: Curso de Nivel Avanzado

O número de participantes no curso de nivel avanzado foi de 49 profesores que a maioría dos casos eran coordinadores abalar ou formaban parte dun centro abalar. Catro profesores fomos os encargados de tutorizar o curso.

\section{Contidos}

Os contidos, distribuídos por módulos, foron os seguintes:

Módulo 1: Coñecemento e utilización dos elementos dunha aula TIC. Xestión e administración avanzada da rede e do sistema operativo. Realización de tarefas de mantemento básico.

Módulo 2: Ferramentas de autor: Ardora, Edilim e ExeLearning.

Módulo 3: Elaboración de mensaxes multimedia: imaxe, son e vídeo.

Módulo 4: Coñecemento e utilización de diferentes estratexias metodolóxicas para a inserción das TIC no deseño curricular. Aprendizaxe colaborativo, simuladores e programación.

Módulo 5: Avaliación coas TIC.

Módulo 6: Mellora da xestión escolar nos centros educativos utilizando as TIC. Emprego a nivel avanzado de programas e plataformas de xestión.

Módulo 7: Dinamización de actividades de formación. Módulo 8: Tarefa final. 


\section{Competencias profesionais do profesorado.}

A competencia profesional que adquirirá o profesorado participante na actividade coa realización do curso é a seguinte:

Módulo 1: Coñecemento e utilización dos elementos dunha aula TIC. Xestión e administración avanzada da rede e do sistema operativo. Realización de tarefas de mantemento básico.

Desenvolver o coñecemento necesario para identificar os elementos que ten unha aula TIC e comprender os cambios aos que estes están suxeitos, co fin de dinamizar a adaptación aos mesmos.

Adquirir un coñecemento básico sobre xestión e administración da rede do centro que permita identificar as súas potencialidades, así como unha identificación inicial das posibles incidencias técnicas.

Desenvolver o coñecemento necesario para a dinamización do profesorado en labores básicas de mantemento básico do sistema operativo dos equipos.

Módulo 2: Ferramentas de autor.

Desenvolver de recursos propios e axeitados a cada aula e ó propio docente.

Ter un coñecemento claro e práctico de como establecer distintas canles de presentación dos recursos ó alumnado en función das necesidades de cada docente (nivel, área, tipo de recurso,...)

Módulo 3: Elaboración de Mensaxes Multimedia.

Incorporación dos fundamentos da creación audiovisual ás producións multimedia.

Manexo de ferramentas de edición de audio, imaxe e vídeo.

Módulo 4. Aprendizaxe colaborativa.

Analizar modelos de integración das TIC no ensino.

Ser capaz de deseñar propostas de traballo cooperativo para o alumnado, baseados na utilización das Tecnoloxías da Información e a Comunicación.

Ampliar o coñecemento sobre o uso da aulavirtual-moodle e outros servizos web.

Módulo 5. TIC e avaliación.

Coñecer e utilizar as posibilidades que ofrecen as TIC para a avaliación formativa

Módulo 6. Mellora da xestión escolar nos centros educativos utilizando as TIC. Emprego a nivel avanzado de programas e plataformas de xestión.

Coñecer a estrutura e servizos que ofrece o portal espazoAbalar á comunidade educativa.

Desenvolver as habilidades necesarias para o manexo dos servizos integrados no portal espazoAbalar

Coñecer as funcionalidades que ofrece a aplicación para familias abalarMóbil e a súa relación con espazoAbalar.

\section{Metodoloxía}

Ao comezo do curso foi obrigatorio enviar unha mensaxe de presentación ao “foro de presentacións". Poderíamos tomar como referencia estes datos:

Nome, destino, ensino, nivel educativo, experiencia ou nivel de coñecementos das tic no ensino, expectativas neste curso, outros comentarios

Este curso estaba deseñado para propiciar o traballo colaborativo mediante o uso de foros que permitan non só expoñer as dúbidas por parte persoas asistentes, senón que tamén se fomentará o debate e intercambio de ideas. Os foros serán útiles para avaliar a participación dos e das asistentes.

Polas propias características deste curso, nivel avanzado, non se considera que poidan aparecer dificultades relacionadas co uso da aula virtual Platega ou coa participación nun curso on-line.

Partindo de que o docente-alumno realizou o nivel medio deste itinerario, onde se fai unha primeira aproximación a cada unha das aplicacións, ou que ten un coñecemento previo de algunha das tres ferramentas, inícianse os tres apartados con contidos que intentan “enlazar” co tratado no citado nivel medio, para recorrer as posibilidades, tanto de agrupamento de contidos alleos como aspectos máis avanzados dos propios programas así como a presentación dos contidos creados.

Abriuse cada un dos módulos segundo o calendario marcado. O alumnado investigaba na "documentación” facilitada e, se o desexa, nos espazos suxeridos nos apartados "recursos” e "para saber máis”. Podería considerarse unha variación das datas inicialmente propostas en función da evolución do curso.

En cada módulo solicítanse tarefas de varios apartados que debían realizarse e enviar despois, a través da propia plataforma Platega, á persoa titora para a súa avaliación dentro do prazo establecido. Era imprescindible a entrega da tarefa definida como "Tarefa final” para a superación do curso.

\section{Seguimento e desenvolvemento do curso}

Este curso desenvolveuse totalmente en rede sen que exista previsión de ningunha sesión presencial. Sabemos que o traballo de titoría resulta polo tanto moi importante no bo funcionamento do mesmo.

O asesoramento no funcionamento da Plataforma, as axudas na resolución de dificultades, as correccións e as avaliacións foron tarefas primordiais no traballo da persoa titora.

Pero ademais da relación directa coa persoa que titoriza, dispoñemos de foros como lugar para a discusión, para a consulta ou para a reflexión. Os foros facilitan a comunicación entre o alumnado e o titor e tamén entre todos os participantes no curso, podendo funcionar como centros de aprendizaxe común onde expoñer as nosas dúbidas ou preguntas, as dos outros participantes, as respostas, as suxestións...

Neste curso dispoñemos dun foro de presentación, un foro xeral de novas, e sobre todo un foro particular para cada módulo para centrar o traballo cooperativo nos temas concretos. Animámosvos pois a todos/as a participar activamente nestes foros fomentando o traballo en común e a aprendizaxe colaborativa.

É importante a visita frecuente e a participación nos foros porque neles podedes atopar aclaracións, respostas ás dúbidas que vaiades tendo e, sobre todo, permítevos manter contacto cos compañeiros e compañeiras de curso, así como coñecer as súas opinións e inquedanzas.

Cada módulo inclúe os contidos conceptuais e as tarefas correspondentes, que deberán ser completadas 
polas persoas participantes na data indicada, e que aparece expresamente reflectida na descrición da tarefa.

\section{Comunicación coas persoas titoras}

Cada vez que comeza un curso de formación a través de PLATEGA, unha das primeiras cousas que deben de facer é presentarse á comunidade de aprendizaxe. Para iso eles atoparan en todos os cursos no primeiro módulo un Foro de presentación de participantes.

Esta primeira mensaxe servirá de presentación tanto co resto da comunidade de aprendizaxe, coma cos titores e titoras do curso.

Existen varias opcións de comunicación co seu titor:

A través dos foros existentes en cada curso, por exemplo, o foro do módulo ou foro de avisos e anuncios. A comunicación que se realiza nos foros é pública, é dicir, calquera participante no curso poderá ler as súas intervencións no foro ou posts.

A través do sistema de mensaxería interna da plataforma, as mensaxes enviadas por este medio son privadas entre quen as emite e o destinatario, xa sexa o titor ou calquera outro participante.

\section{Avaliación}

Este itinerario formativo está deseñado para apoiar ao profesorado no seu cometido de integración das TIC nas aulas coa finalidade de elevar a calidade do ensino. A avaliación da súa repercusión na mellora da docencia e dos resultados académicos forma parte da propia avaliación global da calidade educativa que realiza a Consellería de Cultura, Educación e Ordenación Universitaria.

O profesor titor avaliará as tarefas realizadas e comunicará ao alumnado a valoración das mesmas. Empregarase para isto a seguinte escala: Apto - Non apto

É recomendable realizar as tarefas módulo a módulo ata recibir unha valoración positiva na avaliación, continuando despois co módulo seguinte.

Para acadar a avaliación positiva final do curso é necesario realizar todas as tarefas obrigatorias, e obter unha avaliación positiva de todas elas.

Para favorecer o funcionamento do curso recomendamos que non se envíen novas tarefas ata que se confirme a superación do módulo anterior.

É importante cumprir cos prazos de envío das tarefas solicitadas en cada módulo, e mandar correctamente os arquivos solicitados que conteñan as tarefas pertinentes de cada módulo.

Os módulos incluían tarefas voluntarias que se propoñían ao alumnado como unha forma de afianzar os contidos traballados durante o módulo, pero que non terían carácter obrigatorio nin foron cualificadas.

\section{Enquisa final e conclusións}

Unha vez finalizado o curso realízase a enquisa final para valorar aspectos claves deste.
Tabla 1. Resultados enquisa participantes.

\begin{tabular}{|l|l|}
\hline Media por grupo & Media actividade 4.26 \\
Docencia 4.49 & Participantes da enquisa \\
Organización 4.02 & 42 de49 \\
\hline
\end{tabular}

Preguntas puntuables

Valor das puntuacións para as preguntas da enquisa: (1)mal, (2)regular, (3)suficiente, (4)ben, (5)moi ben

\section{Organización}

1. Utilidade para a docencia e o traballo de aula

2. Duración da actividade

3. Modalidade utilizada para esta actividade

4. Adecuación da secuenciación dos contidos

5. Adecuación dos obxectivos desta actividade

6. Pertinencia dos contidos

7. Relación do coordinador ou coordinadora cos asistentes

8. Calidade dos materiais do curso

9. Grado de dificultade

10. Valoración da aprendizaxe en relación $\cos$

coñecementos previos á actividade

11. Cualificación proporcionada

12. Facilidade de comprensión da documentación

13. Adecuación das datas de celebración

14. Adecuación e deseño das tarefas de aprendizaxe

15. Cumprimento das expectativas da actividade

$\begin{array}{lll}\begin{array}{c}\text { En } \\ \text { branco }\end{array} & \text { Media } & \text { Moda } \\ 0 & 4.12 & 4 \\ 0 & 3.93 & 4 \\ 1 & 4.61 & 5 \\ 0 & 4.1 & 5 \\ 1 & 4.12 & 4 \\ 0 & 4.02 & 4 \\ 1 & 4.41 & 5 \\ 1 & 3.98 & 4 \\ 1 & 3.71 & 4 \\ 0 & 3.9 & 4 \\ 1 & 4.02 & 4 \\ 0 & 4.14 & 4 \\ 1 & 3.78 & 4,5 \\ 0 & 3.98 & 4 \\ 0 & 3.67 & 4\end{array}$

Preguntas de resposta libre

Destacamos algunhas das respostas:

\section{Organización}

Propostas derivadas do desenvolvemento da actividade

- Non repetir contidos e así ter máis tempo para o resto (ou incrementar as 50 horas actuais).

- $\quad$ Creo que se se fai a conciencia leva máis horas das que se reflicten no curso.

- Esta formación debería chegar cada vez a máis profesorado, pois é o que nos espera, ou o alumnado nos vai superar.

- Un ou dos exemplos de cada actividades en pdf ou videotitoriais de como se daría cada actividade tipo paso a paso

- Deseñar máis tarefas colaborativas.

- Edición de vídeo. Cursos específicos e prácticos.

- As datas de celebración, penso que sería mellor nos primeiro e segundo trimestres, xa que nestas datas hai moita carga de traballo e o cansazo vaise notando.

- Gustaríame un curso específico de TIC para PT e AL, si no pode ser xeneral, por patoloxías.

- Incluír algún módulo sobre xestión de redes que nos permitan solucionar problemas básicos que poden xurdir nos centros.

- Este curso resulta moi sinxelo respecto ao medio, no que as actividades eran mais complicadas, tiña moitos mais contidos e o tempo sempre era xusto. Penso que deberían estruturarse mellor.

- Non existan tantas tarefas de debater.

- $\quad$ Creo que o aprendido sérveme para desenvolver actividades cos meus alumnos e dinamizar a utilización das Tics no meu centro.

- Maior acceso á formación específica en S.O. Uso de máis ferramentas adaptadas para Infantil.

- $\quad$ Maior difusión das ferramentas entre os docentes. 


\section{$O$ que estivo ben foi}

- Tanto o material facilitado coma os enlaces externos eran moi bos e facilitaban moito as tarefas.

- Que fora en rede

- BEN GUSTOUME A FORMACIÓN.

- As valoracións dos compañeiros sobre as tarefas presentadas.

- Os contidos son moi axeitados ao esperado. Ademais a relación cos titores foi moi boa.

- A min interesoume máis a parte de fotografía, audío, vídeo, programas como powtoon...

- $\quad$ A variedade dos contidos e experiencias do curso. A cercanía dos relatores e máis o coordinador a a súa rapidez en resolver dúbidas.

- A secuenciación.

- Ver como traballan os compañeir@s e as súas opinión sobre e experiencias Coñecer novos programas: Ardora Exelearning Os coordinadores resolver as dúbidas rapidamente

- A atención, seguimento e apoio dos titores e coordinadores. Unha sorte compartir esta actividade con xente tan profesional e humana.

- $\quad$ Para min, cumpriu as expectativas.

- O curso en xeral. Aprendín cousas novas aínda que a algún módulo non lle vin moita utilidade.

- $\quad$ Os enlaces que servían para entender o verdadeiro sentido das TIC. Un recurso non só como tal senón como ferramenta que nos leve a reflexión e a adquisición de coñecementos.

- Considero en xeral que todo estivo á altura das expectativas que tiña. É importante ter unha formación inicial axeitada para aproveitar o curso.

- $\quad$ As tarefas desenvoltas que foron de utilidade para a docencia e aplicación na aula.

- A cantidade de aspectos tratados.

- Aprendín a utilizar un feixe de novos recursos que teñen unha gran aplicabilidade no meu facer diario.

- Os debates abertos sobre a formación e o recoñecemento do traballo de tódolos compañeiros.

- Os contidos, a temporalización e a dificultade das tarefas ....

\section{Debería mellorarse}

- Atopei o curso con poucos contidos e moita reflexión persoal.

- $\quad$ Todo ben, non vexo nada que indicar.

- Algúns dos contidos xa se traballan no nivel intermedio.

- $\quad$ A redacción do pedido nas tarefas. Resultoume ás veces difícil comprender o que se pedía, sobre todo porque moita terminoloxía pedagóxica é descoñecida para mín.

- $\quad$ Concreción dalgunha actividade. (Tarefa 7)

- Un nivel máis avanzado para este curso. Enfocalo máis á creación de contidos con outro tipo de material que xa existe actualmente nas aulas, tipo aprendizaxe móbil, con actividades para crear apps.
- Contidos, rigor, cumprimento dos prazos en igualdade para todo o mundo...

- A multiplataforma. No me parece ben que se propoñan actividades a cales algúns usuarios no podemos optar por ter IOS, (exemplo: Ardora) deberían avisalo nos requisitos

- Coido que foi un curso moi completo

- Ter acceso a toda a documentación en formato pdf ou libro electrónico a tódolos contidos. . Maior formación no tema de redes en canto á xestión.

- Incluír outros contidos como a realidade aumentada

- Persoalmente daría mais tempo para o desenrolo das actividades, iniciando antes o curso e acabando antes de que comece a temporada de avaliacións finais.

- $\quad$ A escasa participación nos foros.

\section{Conclusión}

O grupo participante no curso de nivel avanzado estiman que as TIC son unhas ferramentas moi útil para o centro para desenvolver o traballo nas aulas TIC. Permite acceder a fontes variadas de información con rapidez baixo a tutela do profesor que poderá ir dirixindo a busca e aconsellando na selección dos contidos aos alumnos.

Aínda que todos os cambios provocan sempre algunha inseguridade, a medida en que fomos vendo as potencialidades e usos didácticos das diferentes ferramentas da web 2.0, a boa disposición e interese do profesorado polas actividades foron cada vez maiores.

Suxerimos que paralelamente ao curso experimentasen levando as tarefas que se propoñen situacións reais de aula, valorando as vantaxes que achegan ao ensino e creando pouco a pouco a vosa propia estrutura TIC ou participando da dinamización TIC do voso centro.

Por outra parte, perseguiamos con este curso aumentar a preparación do profesorado no uso das TIC e das ferramentas 2.0, coa finalidade de que a devandita capacitación redunde na formación do noso alumnado en canto á competencia dixital. Esta competencia dixital irase construíndo paso a paso a través da incorporación das TIC na metodoloxía dos docentes, realización de actividades por parte dos nenos/as, etc.

\section{Referencias}

Competencias dixitais (Portal Educativo Consellería de Educación. Xunta de Galicia.) Recuperado de http://www.edu.xunta.es/web/node/6961

Platega (Aula Virtual do profesorado de Galicia) Recuperado de https://www.edu.xunta.es/platega2

ORDE de 14 de maio de 2013 de convocatoria,recoñecemento, certificación e rexistro das actividades de formación permanente do profesorado en Galicia (DOG Núm 96 do 22 de maio de 2013) 